\title{
MEMAHAMI DUNIA ANAK MELALUI PUISI DI DALAM TABLOID LINTANG
}

\author{
Oleh: I Ketut Sudewa \\ Program Studi Sastra Indonesia \\ Fakultas Ilmu Budaya Universitas Udayana \\ Jl. Nias No 13 Sanglah Denpasar-Bali \\ Email: sudewa.ketut@yahoo.co.id
}

\begin{abstract}
Children express their feelings and thoughts in literary works (poetry) that are created naturally and honestly. They express their world in a beautiful and happy way. Therefore, it is important to understand the world of children expressed in the literary works they create. In this study, discussed about the world of children depicted in children's poetry published in the Lintang tabloid published in January to November 2017. The problems discussed are (1) how the child's world image in poetry contained in the Lintang Tabloid; and (2) how children express their world through poetry in the Lintang tabloid. The method used is a qualitative method that focuses on library studies with techniques of reading, listening, note taking, and interpretation. The theory used is semiotic theory.

The results showed that the children's poetry in the Lintang Tabloid published in the Lintang tabloid published in January to November 2017 generally contained five themes, namely: the environment, animals or animals, profession, plants, and love of the motherland. All these themes are expressed with the feelings and thoughts of the child's world and dominantly expressed by using the language style of repetition, metaphor, and personification.
\end{abstract}

Keywords: understanding, the world of children, poetry

\section{Pendahuluan}

Pengarang memiliki pesan dan ide yang ingin diungkapkan kepada masyarakat pembaca melalui karya sastra yang diciptakan berdasarkan renungan peribadi atau hasil interaksi dengan lingkungan sosialnya. Damono (1978:1) mengatakan bahwa karya sastra menampilkan gambaran kehidupan dan kehidupan itu sendiri adalah suatu kenyataan sosial. Kenyataan sosial yang dihadapi oleh pengarang diolah berdasarkan kemampuan imajinasi yang dimilikinya. Hasil olahan imajinasi pengarang inilah yang diwujudkan ke dalam bentuk karya sastra. Begitu juga halnya dengan anak-anak sebagai pengarang, khususnya penyair akan melalui proses yang sama dan menghasilkan sastra anak. Penelitian terhadap sastra anak belum banyak dilakukan oleh para peneliti sastra sastra.

Di dalam penelitian ini, dibahas tentang memahami dunia anak melalui karya sastra berbentuk puisi ciptaan anak-anak di dalam tabloid Lintangyang dimuat antara Januari sampai November tahun 2017.Semua puisi tersebut telah diterbitkan oleh Dinas Pendidikan Provinsi Bali dengan judul Impianku Antologi Puisi Anak (2017). Di dalam antologi ini dimuat 60 sajak yang ditulis oleh 60 anak-anak siswa Sekolah Dasar sampai Sekolah Menengah Pertama.

Dunia anak melalui pikirannya yang masih polos mengekspresikan imajinasinya ke dalam bentuk puisi. Di dalamnya ada harapan anak, penilaian anak, pengungkapan perasaan anak terhadap diri dan lingkungannya. Persoalan ini menjadi sangat penting diperhatikan oleh pemerintah di dalam menyusun kebijakan dalam membangun literasi dan karakter bangsa yang sejati, khususnya menyangkut kedidupan anak-anak sebagai penerus bangsa.

Berdasarkan latar belakang di atas, maka permasalahan yang dibahas di dalam penelitian ini adalah: (1) bagaimana gambaran dunia anak di dalam puisi yang dimuat di dalam tabloid Lintang; dan (2) bagaimana cara anak-anak mengekspresikan dunianya melalui puisi di dalam tabloid Lintang. Dengan dua permasalahan ini diharapkan dapat memahami dunia anak melalui puisi yang dimuat di dalam tabloid Lintang, khususnya yang dimuat antara Januari sampai November tahun 2017.

Tujuan khusus penelitian ini berkaitan dengan permasalahan yang telah ditentukan, yaitu untuk memahami dunia anak melalui puisi di dalam tabloid Lintang. Di samping itu, untuk 
menemukan cara anak-anak mengekspresikan pikirannya di dalam puisinya tersebut. Dengan tujuan khusus tersebut hasilnya diharapkan berguna dalam menyusun kebijakan yang berkaitan dengan penguatan karakter bangsa, khususnya anak-anak.

Urgensi atau keutamaan penelitian ini adalah ditemukannya pikiran dan perasaan anak-anak di dalam puisi yang dimuat di dalam tabloid Lintang. Temuan ini menjadi penting dan urgen untuk membaca tanda-tanda zaman dunia anak dan dapat menjadi tuntutan dalam menyukseskan pembangunan nasional, sekaligus membangun budaya litersi dalam masyarakat, khususnya anakanak sebagai penerus bangsa.

Potensi hasil yang bisa didapat hingga akhir masa penelitian adalah dipahaminya dunia anak beserta dinamikanya di dalam karya sastra berbentuk puisi yang dimuat di dalam tabloid Lintang. Di samping itu, ditemukan cara serta teknik anak-anak dalam menyampaikan pikiran dan idenya tersebut. Dalam jangka panjang hasil penelitian ini dapat dijadikan model penelitian terhadap penelitian sastra anak di masa depan dan dapat berkontribusi kepada pemerintah di dalam menyusun kebijakan yang berkaitan dengan masalah pembangunan karakter bangsa, khususnya anak-anak.

\section{Tinjauan Pustaka}

Setelah ditelurusi, belum ada penelitian yang khusus membahas tentang dunia anak di dalam karya sastra puisi yang ditulis oleh anakanak di dalam tabloid Lintang. Penelitian ini penting untuk melihat gambaran pikiran dan ide anak yang terkandung di dalam puisi yang dimuat di dalam tabloid tersebut yang secara langsung atau tidak langsung merupakan cermin dari dunia anak secara umum di dalam realita kehidupan sosial masyarakat. Hal inilah yang menyebabkan penelitian ini menjadi penting dilakukan tidak hanya dalam konteks keilmuan, tetapi juga dalam konteks realitas sosial.

Untuk memahami dunia anak di dalam puisi yang dimuat di dalam tabloid Lintang digunakan teori semiotik sebagai teori utama dan ditunjang oleh teori lain yang relevan ketika dilakukan analisis data. Dengan teori ini diharapkan permasalahan yang ditentukan dapat dipecahkan dan dapat menghasilkan penelitian yang valid dan dapat dipertanggungjawabkan secara ilmiah.
Teori semiotikberangkat dari pemahaman bahwa segala sesuatu yang ada di dunia adalah tanda yang memiliki tanda tertentu. Artinya, puisi karya anak-anak di dalam tabloid Lintang merupakan sebuah tanda yang memiliki makna. Oleh karena itu, semua yang diungkapkan oleh anak-anak di dalam puisi tersebut adalah sebuah tanda yang bermakna. Makna ditentukan oleh pembaca sebagai penafsir. Untuk memahami makna tanda-tanda dalam puisi harus didahului dengan pemahaman terhadap unsur-unsur karya sastra bersangkutan yang dikenal dengan pemahaman secara struktural.

Semua fenomena sosial yang ada di dalam masyarakat bisa menjadi objek kajian semiotik karena semiotik diartikan sebagai ilmu tentang tanda-tanda (Noth, 1990:3). Secara konseptual, semiotik mempelajari sistem-sistem, aturan-aturan, dan konvensi-konvensi yang memungkinkan tanda tersebut memiliki arti (Pradopo, 1995:119). Dalam kontek penelitian ini, puisi yang ditulis oleh anak-anak yang dimuat di dalam tabloid Lintang adalah sebuah tanda yang memiliki struktur dan makna tertentu.

Karya sastra, dalam hal ini puisi merupakan sebuah struktur. Struktur puisi menurut Fananie (2000:99-100) dibentuk dari dua struktur yang lebih kecil, yaitu: (a) struktur luar (surface structure), unsur yang berkaitan dengan bentuk puisi, seperti pilihan kata (diksi), bunyi, penempatan kata dalam kalimat, penyusunan kalimat, penyusunan bait dan tifografi; dan (b) struktur dalam (depth structure), unsur yang berkaitan dengan isi atau makna, seperti: tema, pesan, atau makna yang tersirat di balik struktur luar. Djojosuroto (2006:15) mengatakan bahwa sebuah puisi terdiri atas struktur fisik dan struktur batin. Struktur fisik dibangun oleh unsur: diksi, bahasa kias (figurative language), pencitraan (imagery), dan persajakan. Struktur batin dibangun oleh unsur: pokok pikiran (subject matter), tema, nada (tone), suasana (atmosphere), dan amanat (mesagge).

Di dalam penelitian ini digunakan teori semiotik dari Ferdinand de Saussure (dalam Segers, 1978:15; Zaimar, 2008:3) yang mengatakan bahwa ada tiga hal yang terlibat ketika membicarakan tentang tanda-tanda dalam Bahasa, yaitu: (a) tanda (sign), penanda (signifier), dan petanda (signified). Setiap tanda bahasa (dalam hal ini puisi anak di dalam tabloid Lintang) ada dua sisi, yaitu: penanda (bahasa) dan petanda (konsep). Digunakan teori dari Ferdinand 
de Saussure dalam penelitian ini karena teori ini sangat sederhana dan cocok untuk membahas sastra anak (puisi) yang diciptakan dengan kepolosan dan kesederhanaan. Dengan teori ini diharapkan permasalahan yang ditetapkan bisa dibahas dengan baik dan menghasilkan hasil penelitian yang dapat dipertanggungjawabkan secara ilmiah.

Hasil penelitian dengan menggunakan teori semiotik tersebut di atas nantinya dapat berkontribusi dalam pengembangan ilmu pengetahuan khususnya, ilmu sastra. Di samping itu, dapat memperkaya hasil penelitian sastra anak, memperkuat karakter bangsa, dan meningkatkan kemampuan literasi masyarakat, khususnya anak-anak seperti harapan pemerintah.

\section{Metode Penelitian}

Metode penelitian yang digunakan dalam penelitian ini adalah metode kualitatif dan kuantitatif. Metode ini menekankan pada kualitas dan kuantitas data dengan cara kerja studi pustaka dan teknik hermeneutik (penafsiran) secara logis dan bernalar. Data puisi di dalam tabloid Lintang tahun 2017 diidentifikasi dan diklasifikasi terlebih dahulu dari berbagai sudut, misalnya: tema, nama penyair, dan asal sekolah. Untuk membahas permasalahan yang ditentukan dibahas melalui tema mayoritas puisi di dalam tabloid tersebut.

\section{Pembahasan}

Puisidi dalam tabloid Lintang tahun 2017 yang telah diterbitkan dalam bentuk buku dengan judul Impianku Antologi Puisi Anak (2017) memuat 60 puisi. Sebelum dilakukan pembahasan tentang permasalahan yang telah ditetapkan, terlebih dahulu disajikan semua puisi dalam tabel berikut.

\begin{tabular}{|c|c|c|c|c|}
\hline $\begin{array}{l}\mathbf{N} \\
\mathbf{0}\end{array}$ & $\begin{array}{c}\text { Judul } \\
\text { puisi } \\
\end{array}$ & Tema & Penyair & $\begin{array}{c}\text { Asal } \\
\text { Sekolah } \\
\end{array}$ \\
\hline 1 & Hujan & $\begin{array}{l}\text { Lingkunga } \\
\mathrm{n} \text { hidup }\end{array}$ & $\begin{array}{l}\text { Windy } \\
\text { Apsari }\end{array}$ & $\begin{array}{l}\text { SD } 18 \\
\text { Dangri } \\
\text { Dps }\end{array}$ \\
\hline 2 & Banjir & $\begin{array}{l}\text { Lingkunga } \\
\mathrm{n} \text { hidup }\end{array}$ & $\begin{array}{l}\text { I Gusti } \\
\text { Putu } \\
\text { Rinandari }\end{array}$ & \begin{tabular}{|l} 
SD \\
Wirya \\
Sedana \\
Blahbatu \\
h \\
Gianyar \\
\end{tabular} \\
\hline 3 & $\begin{array}{l}\text { Sepeda } \\
\text { Baruku }\end{array}$ & $\begin{array}{l}\text { Kepemilik } \\
\text { an }\end{array}$ & $\begin{array}{l}\text { Yadnya } \\
\text { Ningtyas }\end{array}$ & $\begin{array}{l}\text { SD } \\
\text { Dwijendr }\end{array}$ \\
\hline
\end{tabular}

\begin{tabular}{|c|c|c|c|c|}
\hline & & & & a Dps \\
\hline 4 & Buku & Cinta Ilmu & $\begin{array}{l}\text { Jatismara } \\
\text { Putra }\end{array}$ & $\begin{array}{l}\text { SD } \\
\text { Saraswat } \\
\text { i } 4 \text { Dps }\end{array}$ \\
\hline 5 & Matahari & $\begin{array}{l}\text { Keindahan } \\
\text { alam }\end{array}$ & Fendy & \begin{tabular}{|l|} 
SD \\
Saraswat \\
i 4 Dps
\end{tabular} \\
\hline 6 & Pahlawan & $\begin{array}{l}\text { Nasionais } \\
\text { me }\end{array}$ & $\begin{array}{l}\text { Putu } \\
\text { Jyotira } \\
\text { Dias }\end{array}$ & \begin{tabular}{|l|} 
SD \\
Saraswat \\
i 5 Dps
\end{tabular} \\
\hline 7 & $\begin{array}{l}\text { Kupu- } \\
\text { kupu }\end{array}$ & $\begin{array}{l}\text { Keindahan } \\
\text { alam }\end{array}$ & \begin{tabular}{|l|} 
Ni Kadek \\
Devia \\
Pradnya A
\end{tabular} & \begin{tabular}{|l|} 
SD \\
Saraswat \\
i 4 Dps \\
\end{tabular} \\
\hline 8 & Biolaku & $\begin{array}{l}\text { Kepemilik } \\
\text { an }\end{array}$ & Intan & $\begin{array}{l}\text { SD } \\
\text { Dwijendr } \\
\text { a Dps }\end{array}$ \\
\hline 9 & Ayamku & $\begin{array}{l}\text { Kepemilik } \\
\text { an }\end{array}$ & Surista & $\begin{array}{l}\text { SD 2 B. } \\
\text { Bulan } \\
\text { Gianyar }\end{array}$ \\
\hline 10 & $\begin{array}{l}\text { Taman } \\
\text { Bunga }\end{array}$ & $\begin{array}{l}\text { Keindahan } \\
\text { alam }\end{array}$ & $\begin{array}{l}\text { AA Rani } \\
\text { Prabaswari } \\
\text { Dewi }\end{array}$ & $\begin{array}{l}\text { SD } \\
\text { Dwijendr } \\
\text { a Dps }\end{array}$ \\
\hline 11 & $\begin{array}{l}\text { Kupu- } \\
\text { Kupu }\end{array}$ & $\begin{array}{l}\text { Keindahan } \\
\text { alam }\end{array}$ & $\begin{array}{l}\text { Ni } \\
\text { KadekTari } \\
\text { sa Sintia } \\
\text { Dewi } \\
\end{array}$ & $\begin{array}{l}\text { SD } \\
\text { Dwijwnd } \\
\text { ra Dps }\end{array}$ \\
\hline 12 & Kebunku & $\begin{array}{l}\text { Keindahan } \\
\text { alam }\end{array}$ & $\begin{array}{l}\text { Desi Arta } \\
\text { Susanti }\end{array}$ & \begin{tabular}{|l} 
SD \\
Dwijwnd \\
ra Dps \\
\end{tabular} \\
\hline 13 & Anjing & $\begin{array}{l}\text { Kepemilik } \\
\text { an }\end{array}$ & $\begin{array}{l}\text { Cok Bima } \\
\text { Aditya } \\
\text { Ambara P }\end{array}$ & \begin{tabular}{|l} 
SD \\
Saraswat \\
i 4 Dps \\
\end{tabular} \\
\hline 14 & $\begin{array}{l}\text { Pulau } \\
\text { Dewata }\end{array}$ & $\begin{array}{l}\text { Keindahan } \\
\text { Bali }\end{array}$ & $\begin{array}{l}\text { Putu Novi } \\
\text { Dian } \\
\text { Sukmawati }\end{array}$ & \begin{tabular}{|l|} 
SD \\
Saraswat \\
i 4 Dps
\end{tabular} \\
\hline 15 & Bunga & $\begin{array}{l}\text { Keindahan } \\
\text { alam }\end{array}$ & $\begin{array}{l}\text { Dewa A } \\
\text { Vida } \\
\text { Pradnyand } \\
\text { ari }\end{array}$ & \begin{tabular}{|l|} 
SD \\
Saraswat \\
i 5 Dps
\end{tabular} \\
\hline 16 & $\begin{array}{l}\text { Calonaran } \\
\text { g }\end{array}$ & $\begin{array}{l}\text { Cinta } \\
\text { budaya }\end{array}$ & Wisnu & \begin{tabular}{|l} 
SD Cipta \\
Darma \\
Dps \\
\end{tabular} \\
\hline 17 & \begin{tabular}{|l|} 
Jendela \\
Ilmu
\end{tabular} & Cinta Ilmu & $\begin{array}{l}\text { GB Satya } \\
\text { Nanda }\end{array}$ & \begin{tabular}{|l|} 
SD \\
Saraswat \\
i 5 Dps \\
\end{tabular} \\
\hline 18 & $\begin{array}{l}\text { Sepatu } \\
\text { Baru }\end{array}$ & $\begin{array}{l}\text { Kepemilik } \\
\text { an }\end{array}$ & \begin{tabular}{|l} 
Tri \\
Dharma \\
Putra
\end{tabular} & $\begin{array}{l}\text { SD } \\
\text { Dwijendr } \\
\text { a Dps }\end{array}$ \\
\hline 19 & Baliku & $\begin{array}{l}\text { Keindahan } \\
\text { Bali }\end{array}$ & $\begin{array}{l}\mathrm{Pt} \text { Novi } \\
\text { Dian } \\
\text { Sukmawati }\end{array}$ & \begin{tabular}{|l} 
SD \\
Saraswat \\
i 4 Dps \\
\end{tabular} \\
\hline 20 & Dokter & Profesi & $\mathrm{Pt} \quad \mathrm{Ayu}$ & SD \\
\hline
\end{tabular}




\begin{tabular}{|c|c|c|c|c|}
\hline & & & $\begin{array}{l}\text { Gita } \\
\text { Kinanti P }\end{array}$ & $\begin{array}{l}\text { Saraswat } \\
\text { i } 5 \text { Dps }\end{array}$ \\
\hline 21 & Guru & Profesi & $\begin{array}{l}\text { Putu } \\
\text { Dimas } \\
\text { Putra P.M }\end{array}$ & $\begin{array}{l}\text { SD } \\
\text { Saraswat } \\
\text { i } 5 \text { Dps }\end{array}$ \\
\hline 22 & Polisi & Profesi & $\begin{array}{l}\text { Widya } \\
\text { Putri }\end{array}$ & \begin{tabular}{|l|} 
SD \\
Saraswat \\
i 5 Dps \\
\end{tabular} \\
\hline 23 & $\begin{array}{l}\text { Selamat } \\
\text { Pagi }\end{array}$ & $\begin{array}{l}\text { Keindahan } \\
\text { alam }\end{array}$ & $\begin{array}{l}\text { Angelica } \\
\text { Maysie }\end{array}$ & \begin{tabular}{|l} 
SD \\
Saraswat \\
i 5 Dps
\end{tabular} \\
\hline 24 & Sahabat & $\begin{array}{l}\text { Persahabat } \\
\text { an }\end{array}$ & $\begin{array}{l}\text { Murtini } \\
\text { Paramita }\end{array}$ & $\begin{array}{l}\text { SD } \\
\text { Saraswat } \\
\text { i } 5 \text { Dps }\end{array}$ \\
\hline 25 & Mawar & $\begin{array}{l}\text { Keindahan } \\
\text { alam }\end{array}$ & $\begin{array}{l}\text { I Gst Made } \\
\text { Anggita } \\
\text { Mila D }\end{array}$ & \begin{tabular}{|l} 
SD \\
Saraswat \\
i 4 Dps
\end{tabular} \\
\hline 26 & $\begin{array}{l}\text { Tanah } \\
\text { Airku }\end{array}$ & $\begin{array}{l}\text { Nasionalis } \\
\text { me }\end{array}$ & $\begin{array}{l}\text { Della } \\
\text { Puspita D }\end{array}$ & \begin{tabular}{|l} 
SD \\
Saraswat \\
i 5 Dps
\end{tabular} \\
\hline 27 & Kepiting & $\begin{array}{l}\text { Lingkunga } \\
\mathrm{n} \text { hidup }\end{array}$ & Yudi Bijak & \begin{tabular}{|l|} 
SD \\
Saraswat \\
i 5 Dps \\
\end{tabular} \\
\hline 28 & Impianku & & $\begin{array}{l}\text { AA Istri } \\
\text { Ary } \\
\text { Anggreni }\end{array}$ & \begin{tabular}{|l} 
SD \\
Saraswat \\
i 5 Dps
\end{tabular} \\
\hline 29 & Penari & $\begin{array}{l}\text { Nasionalis } \\
\text { me }\end{array}$ & $\begin{array}{l}\mathrm{Ni} P t \\
\text { Pradnya } \\
\text { Swandewi }\end{array}$ & \begin{tabular}{|l} 
SD \\
Saraswat \\
i 5 Dps
\end{tabular} \\
\hline 30 & $\begin{array}{l}\text { Bunga } \\
\text { Jempiring }\end{array}$ & $\begin{array}{l}\text { Keindahan } \\
\text { alam }\end{array}$ & $\begin{array}{l}\text { Kadek } \\
\text { Arya } \\
\text { Advaitha } \\
\text { Dewi } \\
\end{array}$ & \begin{tabular}{|l} 
SD \\
Saraswat \\
i 4 Dps
\end{tabular} \\
\hline 31 & Taman & $\begin{array}{l}\text { Keindahan } \\
\text { alam }\end{array}$ & $\begin{array}{l}\text { Ni Pt Clara } \\
\text { Puspita } \\
\text { Arta A }\end{array}$ & \begin{tabular}{|l} 
SD \\
Saraswat \\
i 5 Dps
\end{tabular} \\
\hline 32 & Api Suci & $\begin{array}{l}\text { Semangat } \\
\text { hidup }\end{array}$ & $\begin{array}{l}\text { Deshinta } \\
\text { A.P }\end{array}$ & $\begin{array}{l}\text { SD } \\
\text { Saraswat } \\
\text { i } 4 \text { Dps } \\
\end{array}$ \\
\hline 33 & Hutan & $\begin{array}{l}\text { Lingkunga } \\
\mathrm{n} \text { hidup }\end{array}$ & $\begin{array}{|ll|}\text { IB } & \text { Ide } \\
\text { Yogi } & \\
\text { Swara } & \\
\end{array}$ & \begin{tabular}{|l} 
SD \\
Saraswat \\
i 4 Dps
\end{tabular} \\
\hline 34 & $\begin{array}{l}\text { Keragama } \\
\text { n Budaya }\end{array}$ & $\begin{array}{l}\text { Nasionalis } \\
\text { me }\end{array}$ & $\begin{array}{l}\text { AAN } \\
\text { Bramanda } \\
\text { M.S }\end{array}$ & \begin{tabular}{|l} 
SD \\
Saraswat \\
i 5 Dps
\end{tabular} \\
\hline 35 & Indonesia & $\begin{array}{l}\text { Nasionalis } \\
\text { me }\end{array}$ & \begin{tabular}{|l} 
Amelia \\
Kusuma \\
Purnama S
\end{tabular} & \begin{tabular}{|l} 
SD \\
Saraswat \\
i 5 Dps
\end{tabular} \\
\hline 36 & \begin{tabular}{|l} 
Kodok \\
yang \\
malang
\end{tabular} & $\begin{array}{l}\text { Lingkunga } \\
\mathrm{n} \text { hidup }\end{array}$ & $\begin{array}{l}\text { Victoria } \\
\text { Ananda } \\
\text { Savitri }\end{array}$ & $\begin{array}{l}\text { SD } \\
\text { Saraswat } \\
\text { i } 5 \text { Dps }\end{array}$ \\
\hline 37 & Sekolah & Lingkunga & Ketut Ayu & SD \\
\hline
\end{tabular}

\begin{tabular}{|c|c|c|c|c|}
\hline & & $\mathrm{n}$ hidup & $\begin{array}{l}\text { Dewi } \\
\text { Lestari }\end{array}$ & $\begin{array}{l}\text { Saraswat } \\
\text { i } 5 \text { Dps }\end{array}$ \\
\hline 38 & Desaku & $\begin{array}{l}\text { Keindahan } \\
\text { alam }\end{array}$ & $\begin{array}{lr}\text { Ni } & \text { Md } \\
\text { Ayu } & \text { Sri } \\
\text { Ratih } & \text { A }\end{array}$ & \begin{tabular}{|l} 
SD \\
Saraswat \\
i 5 Dps
\end{tabular} \\
\hline 39 & $\begin{array}{l}\text { Sekolahk } \\
\text { u }\end{array}$ & $\begin{array}{l}\text { Lingkunga } \\
\text { n hidup }\end{array}$ & $\begin{array}{l}\text { AA Putri } \\
\text { Cahya } \\
\text { Valentina }\end{array}$ & $\begin{array}{l}\text { SD } \\
\text { Saraswat } \\
\text { i } 5 \text { Dps }\end{array}$ \\
\hline 40 & $\begin{array}{l}\text { Sepatu } \\
\text { Baruku }\end{array}$ & $\begin{array}{l}\text { Kepemilik } \\
\text { an }\end{array}$ & Nanda & \begin{tabular}{|l} 
SD \\
Wirya \\
Sedana \\
Blahbatu \\
h \\
Gianyar
\end{tabular} \\
\hline 41 & Buku & Cinta Ilmu & $\begin{array}{l}\text { Ni Luh Pt } \\
\text { Delia } \\
\text { Asenia P }\end{array}$ & \begin{tabular}{|l} 
SD \\
Dwijendr \\
a Dps
\end{tabular} \\
\hline 42 & Matahari & $\begin{array}{l}\text { Keindahan } \\
\text { alam }\end{array}$ & $\begin{array}{l}\text { Pt Agus } \\
\text { Prima } \\
\text { Wardana }\end{array}$ & $\begin{array}{l}\text { SD } \\
\text { Dwijendr } \\
\text { a Dps }\end{array}$ \\
\hline 43 & Jam & $\begin{array}{l}\text { Kepemilik } \\
\text { an }\end{array}$ & $\begin{array}{l}\text { Ni Ketut } \\
\text { Julianti } \\
\text { Astini } \\
\end{array}$ & $\begin{array}{l}\text { SD } \\
\text { Dwijendr } \\
\text { a Dps }\end{array}$ \\
\hline 44 & Sahabat & $\begin{array}{l}\text { Persahabat } \\
\text { an }\end{array}$ & $\begin{array}{l}\text { Made Ayu } \\
\text { Intan P }\end{array}$ & \begin{tabular}{|l|} 
SD \\
Dwijendr \\
a Dps
\end{tabular} \\
\hline 45 & $\begin{array}{l}\text { Keluargak } \\
\mathrm{u}\end{array}$ & $\begin{array}{l}\text { Sayang } \\
\text { keluaga }\end{array}$ & Dirga & \begin{tabular}{|l|} 
SD \\
Jambe \\
Agung \\
Blahbatu \\
h \\
Gianyar
\end{tabular} \\
\hline 46 & $\begin{array}{l}\text { Layang- } \\
\text { layang }\end{array}$ & $\begin{array}{l}\text { Kepemilik } \\
\text { an }\end{array}$ & $\begin{array}{l}\text { Komang } \\
\text { Indra }\end{array}$ & $\begin{array}{l}\text { SD } 2 \text { B. } \\
\text { Bulan } \\
\text { Gianyar } \\
\end{array}$ \\
\hline 47 & Lebah & $\begin{array}{l}\text { Lingkunga } \\
\mathrm{n} \text { hidup }\end{array}$ & $\begin{array}{l}\text { Komang } \\
\text { Ayu Sonia } \\
\text { A }\end{array}$ & \begin{tabular}{|l} 
SD \\
Saraswat \\
i 4 Dps
\end{tabular} \\
\hline 48 & Kucing & $\begin{array}{l}\text { Kepemilik } \\
\text { an }\end{array}$ & \begin{tabular}{|l|} 
Wayu \\
Dyausa
\end{tabular} & \begin{tabular}{|l} 
SD \\
Saraswat \\
i 5 Dps
\end{tabular} \\
\hline 49 & \begin{tabular}{|l|} 
Taman \\
Bungaku
\end{tabular} & $\begin{array}{l}\text { Keindahan } \\
\text { alam }\end{array}$ & $\begin{array}{ll}\mathrm{Ni} & \mathrm{Md} \\
\text { Ayu } & \\
\text { Nindya } & \mathrm{D}\end{array}$ & $\begin{array}{l}\text { SD } \\
\text { Dwijendr } \\
\text { a Dps }\end{array}$ \\
\hline 50 & Kelinciku & $\begin{array}{l}\text { Kepemilik } \\
\text { an }\end{array}$ & $\begin{array}{l}\text { Komang } \\
\text { Ayu } \\
\text { Berlian P }\end{array}$ & \begin{tabular}{|l|} 
SD \\
Saraswat \\
i 4 Dps
\end{tabular} \\
\hline 51 & \begin{tabular}{|l|} 
Suara \\
Kerindua \\
n
\end{tabular} & Kerinduan & $\begin{array}{l}\text { Ni Luh Pt } \\
\text { Novia } \\
\text { Karlina CS }\end{array}$ & \begin{tabular}{|l|} 
SD \\
Saraswat \\
i 4 Dps
\end{tabular} \\
\hline 52 & $\begin{array}{l}\text { Gururan } \\
\text { Daun di }\end{array}$ & Cinta alam & $\begin{array}{l}\text { I Md Dwi } \\
\text { Semadi }\end{array}$ & \begin{tabular}{|l|} 
SD \\
Saraswat
\end{tabular} \\
\hline
\end{tabular}




\begin{tabular}{|l|l|l|l|l|}
\hline & $\begin{array}{l}\text { Musin } \\
\text { semi }\end{array}$ & Putra & i 4 Dps \\
\hline 53 & Desaku & $\begin{array}{l}\text { Keindahan } \\
\text { alam }\end{array}$ & $\begin{array}{l}\text { Tito Indra } \\
\text { Prawira N }\end{array}$ & $\begin{array}{l}\text { SD } \\
\text { Saraswat } \\
\text { i } 5 \text { Dps }\end{array}$ \\
\hline 54 & Petani & Profesi & $\begin{array}{l}\text { Ni Pt Sri } \\
\text { Yuristiani }\end{array}$ & $\begin{array}{l}\text { SD } \\
\text { Saraswat } \\
\text { i 4 Dps }\end{array}$ \\
\hline 55 & Alam & $\begin{array}{l}\text { Keindahan } \\
\text { alam }\end{array}$ & $\begin{array}{l}\text { Ika } \\
\text { Frangipani }\end{array}$ & $\begin{array}{l}\text { SD } \\
\text { Saraswat } \\
\text { i 4 Dps }\end{array}$ \\
\hline 56 & $\begin{array}{l}\text { Guruku } \\
\text { Pahlawan } \\
\text { ku }\end{array}$ & Profesi & $\begin{array}{l}\text { Made Dwi } \\
\text { Arya } \\
\text { Widana }\end{array}$ & $\begin{array}{l}\text { SD } \\
\text { Dwijendr } \\
\text { a Dps }\end{array}$ \\
\hline 57 & Kucing & $\begin{array}{l}\text { Kepemilik } \\
\text { an }\end{array}$ & $\begin{array}{l}\text { AA } \\
\text { Sagung } \\
\text { Kaima WP }\end{array}$ & $\begin{array}{l}\text { SD } \\
\text { Kesiman } \\
\text { Dps }\end{array}$ \\
\hline 58 & $\begin{array}{l}\text { Pantai } \\
\text { yang } \\
\text { Indah }\end{array}$ & $\begin{array}{l}\text { Keindahan } \\
\text { alam }\end{array}$ & $\begin{array}{l}\text { I Wayan Pt } \\
\text { Adi } \\
\text { Triguna }\end{array}$ & $\begin{array}{l}\text { SD } \\
\text { Saraswat } \\
\text { i 5 Dps }\end{array}$ \\
\hline 59 & Boneka & $\begin{array}{l}\text { Kepemilik } \\
\text { an }\end{array}$ & $\begin{array}{l}\text { Shani } \\
\text { Alika } \\
\text { Dewi }\end{array}$ & $\begin{array}{l}\text { SD } \\
\text { Saraswat } \\
\text { i 5 Dps }\end{array}$ \\
\hline 60 & Bunga & $\begin{array}{l}\text { Keindahan } \\
\text { alam }\end{array}$ & $\begin{array}{l}\text { Shani } \\
\text { Alika } \\
\text { Dewi }\end{array}$ & $\begin{array}{l}\text { SD } \\
\text { Saraswat } \\
\text { i 5 Dps }\end{array}$ \\
\hline
\end{tabular}

Dari tabel di atas menunjukkan bahwa apabila dilihat dari tema, 17 puisi $(28,3 \%)$ bertema keindahan alam, bertema kepelilikan 12 puisi $(20 \%)$, bertema lingkungan hidup 8 puisi $(13,3 \%)$, bertema nasionalisme 5 puisi $(8,3 \%)$ dan berbagai tema lainnya 18 puisi $(30 \%)$. Apabila dilihat dari jenis kelamin penyair menunjukkan bahwa 40 orang $(66,7 \%)$ berjenis kelamin dan 20 orang $(33,3 \%)$ berjenis kelamin laki-laki. Dilihat dari asal sekolah, maka tampak didominasi oleh siswa Sekolah Dasar (SD) dari Saraswati Denpasar, yakni 24 orang $(40 \%)$ dari SD Saraswati 5 Denpasar, 16 orang $(26,7 \%)$ dari SD Saraswati 4 Denpasar. Kemudian, 12 orang (20\%) siswa SD Dwijendra Denpasar, dan sekolah lainnya 8 orang $(13,3 \%)$.

Untuk memahami dunia anak melalui puisi di dalam tabloid Lintang yang telah dibukukan menjadi Impianku Antologi Puisi Anak (2017), berangkat dari sudut tema 60 puisi yang termuat di dalamnya. Memahami dunia anak tersebut melalui pembahasan permasalahan yang telah ditetapkan dengan menggunakan teori semiotik dari Ferdinand de Saussure.
Seperti yang telah dikemukakan di dalam metode penelitian sebelumnya, bahwa pembahasan permasalahan yang telah ditetapkan berdasarkan mayoritas tema dari seluruh puisi di dalam tabloid Lintang. Dari tabel di atas menunjukkan bahwa mayoritas tema puisi di dalam tabloid tersebut adalah: keindahan alamn 17 puisi (28,3\%), kepemilikan 12 puisi (20\%), dan lingkungan hidup 8 puisi (13,3\%).Di dalam pembahasan tidak semua puisi yang yang ada di dalam setiap tema dibahas, tetapi dibahas beberapa puisi yang ditetapkan secara acak.

\section{a) Tema Keindahan Alam}

Tema keindahan alam merupakan tema yang paling banyak disampaikan oleh penyair. Hal ini dapat dipahami mengingat anak-anak banyak berinteraksi dengan lingkungan alam di sekitarnya. Semuanya termasuk alam dilihat sebagai suatu hal yang indah, damai, dan menarik sesuai dengan dunianya. Keadaan alam yang indah, damai, dan menarik yang dilihat dan dirasakan oleh anak-anak diekspresikan dengan kesederhanaan dan keluguan dalam bentuk puisi. Salah satu contoh puisi berikut bertema keindahan alam adalah puisi karya AA Rani Prabaswari Dewi dari SD Dwijendra Denpasar.

\section{Taman Bunga}

Pagi hari yang indah

Langit yang cerah

Kupu-kupu menari

Riang gembira menyambut pagi

Bunga-bunga berwarna-warni

Seolah-olah bernyanyi

Kusirami sambil bersenandung

Senang hatiku

Melihat taman bunga (hal. 10)

Penanda //taman bunga// mengandung makna atau petanda keindahan karena ada banyak bunga aneka warna apalagi dilihat pada //pagi hari yang indah//. Bagi dunia anak keadaan itu mudah menyentuh perasaannya yang polos dan mengekspresikannya ke dalam bentuk puisi. Keindahan taman bunga pada pagi hari diperkuat kesannya lagi dengan //kupu-kupu menari// dengan gembira menyambut keindahan pagi. Ekspresi keindahan diperkuat lagi dengan cara menggunakan gaya bahasa personifikasi //bungabunga berwarna-warni//seolah-olah bernyayi//. Dengan kepolosan dan kelugasannya penyair mengatakan //senang hatiku//melihat taman bunga//. Secara umum tampak bahwa puisi 
"Taman Bunga" sebagai penanda merujuk kepada petanda atau makna bahwa bagi anak-anak keindahan alam adalah dunia dan hidupnya. Manusia harus bisa melihat hal-hal yang indah di dalam hidup sehingga hidup bisa lebih bermakna.

Keindahan alam bagi dunia anak juga tampak ketika anak-anak melihat matahari pagi yang cerah dan indah. Puisi berjudul "Selamat Pagi" karya Angelica Maysie dari SD Saraswati 5 Denpasar tidak hanya menggambarkan keindahan matahari pagi, tetapi keadaan itu juga dapat memberi semangat di dalam menjalankan kewajiban sebagai siswa. Perhatikanlah puisi tersebut berikut.

Selamat Pagi

Mentari terbit di ufuk timur

Aku terbangun dari lelapku

Terlihat cuaca nan indah

Kian membuatku bersemangat

\section{Semangatku bagaikan api yang membara \\ Dalam sekejap aku telah siap \\ Siap menjalani hariku \\ Hariku yang berwarna}

Wahai kawanku semua!

Kita sebagai generasi penerus bangsa

Tidak boleh seperti babi yang bermalasmalas

Mari sambut pagi dengan semangat (hal. 23)

Pada bait ke-1, penyair menggunakan penanda dengan kombinasi kata-kata yang bernilai sangat puitis dan estetis, seperti kata: 'mentari' (gejala metatesis) dalam baris puisi //mentari terbit di ufuk timur// untuk mengganti kata 'matahari', kata 'lelapku' dalam baris //aku terbangun dari lelapku// untuk menggantikan kata 'tidur', kata 'nan' dalam baris //terlihat cuaca nan indah// untuk mengganti kata 'sangat', dan kata 'kian' dalam baris //kian membuatku bersemangat// untuk menggantikan kata 'semakin'. Tujuannya, untuk membuat puisi lebih puitis dan estetis. Petanda dari bait pertama adalah pagi yang indah dengan sinar matahari terbit membuat penyair terbangun dengan bersemangat melaksanakan kewajibannya.

Penanda pada bait ke-2 menggambarkan kuatnya semangat penyair sehingga dibuka dengan cara menggunakan gaya bahasa perbandingan dan hiperbola //semangatku bagaikan api yang membara//. Gambaran bersemangatnya penyair diperkuat lagi dengan memakai gaya bahasa hiperbola pada baris kedua //hariku yang berwarna// sehingga dalam 'sekejap' penyair sudah siap melaksanakan kewajiban dan 'hariku' yang penuh dengan dinamika serta pasang surut. Petanda bait kedua puisi di atas adalah bahwa anak-anak selalu hidup optimis dan bergembira menjalani kehidupan dunia anak juga dalam melaksanakan kewajiban sebagai seorang anak.

Pada bait ke-3sebagai penanda, penyair mengajak //wahai kawanku semua!// untuk mencontoh diri penyair dalam menjalankan kehidupan. Penyair menggunakan diksi "kawanku" agar kesannya lebih akrab sehingga pesan sampai kepada pembaca (anak-anak) dengan baik. Untuk memperkuat keakraban tersebut, pada baris kedua digunakan kata 'kita' (penyair dan pembaca) //kita sebagai generasi penerus bangsa// tidak malas dan //tidak boleh seperti babi yang bermalas-malas//. Dengan cara menggunakan gaya bahasa perbandingan, penyair mengajak 'kawanku' agar tidak seperti babi yang memiliki watak pemalas dan hanya bisa makan saja. Penyair penutup puisinya dengan mengajak anak-anak yang lain untuk menyambut pagi (kehidupan) dengan bersemangat seperti penyair //mari sambut pagi dengan semangat//. Petanda pada bait ketiga adalah bahwa semua anak-anak harus hidup bersemangat dan siap melaksanakan kewajiban, jangan malas seperti babi.

Keindahan alam juga diungkapkan oleh penyair lainnya, yakni Tito Indra Prawira Negara siswa SD Saraswati 5 Denpasar. Penyair menggambarkan keindahan desanya melalui puisinya yang berjudul "Desaku". Di dalam puisi ini, penyair mengeksplorasi daya estetika secara maksimal ketika berhadapan dengan desanya ('desaku') dengan cara menggunakan gaya bahasa hiperbola. Hampir keseluruhan puisinya menggunakan gaya bahasa ini, hanya satu kali menyisipkan gaya bahasa personifikasi. Perhatikanlah puisi tersebut berikut.
Desaku
Desaku indah
Aku dilahirkan di sana
Alam yang rapi dan bersih
Bunga-bunga semerbak
Menghiasi setiap sudut rumahku
Burung berkicau dengan riang
Ayam berkokok di pagi hari
Embun-embun menetes di dedaunan
Desaku indah, sejuk
Desaku adalah ibuku (hal. 53) 
Penanda bahasa pada bait pertama puisi di atas menunjukkan bahwa penyair memuji keindahan desanya tempat ia dilahirkan //desaku indah// dan //aku diahirkan di sana//. Penggunaan kata ganti 'aku' mengesankan sikap kepemilikan (ego) dan cinta yang kuat dan hal itu merupakan dunianya anak-anak. Kemudian, digambarkan kesempurnaan keindahan desanya dengan cara menggunakan kata-kata yang bernuansa hiperbola, seperti kata: 'rapi dan indah' pada baris ketiga //alam yang rapi dan bersih//, kata 'semerbak' pada baris keempat//bunga-bunga semerbak//, dan kata 'setiap sudut rumahku' pada baris kelima //menghiasi setiap sudut rumahku//. Penggunaan kata-kata tersebut berfungsi untuk memperkuat kesan keindahan desa(ku) di mata pembaca. Petanda bait pertama ini menunjukkan bahwa penyair (aku) bangga dengan keindahan desa dan rumah tempat kelahirannya.

Pada bait kedua, penyair menggunakan penanda bahasa dengan cara menggunakan gaya bahasa hiperbola dan personifikasi. Keindahan desa(ku) tidak hanya digabarkan melalui kehidupan flora, tetapi juga kehidupan fauna. Hal ini menyebabkan keindahan desa(ku) lebih sempurna bagi pembaca. Dengan gaya bahasa hiperbola //burung berkicau dengan riang// menyempurnakan keindahan flora sebelumnya, burung tidak hanya 'berkicau' tetapi juga 'riang'. Suara burung dilengkapi dengan suara //ayam berkokok di pagi hari// yang menandakan kehidupan desa yang alami. Suasana pada pagi hari dengan keindahan flora dan fauna di desa(ku) diperkuat lagi dengan suasana //embun-embun menetes di dedaunan//, sehingga desa(ku) terkesan indah dan sejuk //Desaku indah, sejuk//. Bait kedua ini ditutup dengan baris puisi bergaya bahasa personifikasi //desaku adalah ibuku// karena begitu cinta dan bangganya penyair dengan desa(ku) sehingga desa(ku) dianggap sebagai 'ibuku'. Petanda dari bait puisi ini adalah bahwa aku (penyairu) sangat cinta dan bangga kepada desanya sehingga desa(ku) dianggap sebagai 'ibuku'.

\section{b) Tema Kepemilikan}

Tema kepemilikian menduduki peringkat kedua terbanyak puisi anak-anak di dalam tabloid Lintang tahun 2017, yaitu 12 puisi (20\%). Hal ini dapat dipahami karena kehidupan dunia anak adalah kehidupan serba 'milikku' dan mereka pasti mencintai 'milikku' itu, apalagi 'milikku' itu diberikan oleh keluarga, misalnya: ayah, ibu, atau kakak. Salah satu puisi yang menggambarkan hal tersebut adalah karya Yadnya Ningtyas siswa SD Dwijendra Denpasar berjudul "Sepeda Baruku'.

Sepeda Baruku

Aku punya sepeda baru

Warnanya biru

Dibelikan oleh ayah

Ada gambar bonekanya

Ada keranjangnya

Aku suka sekali naik sepeda

Sepedaku...

Akan kujaga sepedaku

Supaya tidak cepat rusak

Kalau aku ke sekolah

Aku memakai sepedaku (hal.3)

Tema kepemilikan puisi di atas ditandai oleh penanda bahasa dengan penggunaan kata ganti orang pertama tunggal 'ku' atau 'aku'. Pada bait pertama ada nuansa permainan buuyi vokal (asonansi) untuk memperkuat tema kepemilikan. Asonansi dimaksudkan untuk memperkuat kesan indah bagi pembaca //aku punya sepeda baru// dan //warnanya biru// menunjukkan bahwa penyair memakai diksi warna 'biru' untuk 'sepedaku' agar berasonansi dengan kata 'baru' atau ada kombinasi bunyi vokal a, e dan u. Aku (penyair) senang mempunyai sepeda baru berwarna biru yang //dibelikan oleh ayah//. Sepeda baru itu dijelaskan lebih detil melalui baris keempat dan kelima bahwa sepeda yang dibelikan oleh ayah //ada gambar bonekanya// dan //ada keranjangnya//dengan kombinasi bunyi vokal a dan e serta ada gaya bahasa repetisi untuk memperjelas identitas sepeda (aku). Oleh karena itu, //aku suka naik sepeda// dan diperjelas lagi pada bait ketiga, yakni //kalau aku ke sekolah//, maka //aku memakai sepedaku//.Ada gambaran bahwa penyair sangat mencintai //sepedaku...// itu. Dengan rasa cinta, banggga, dan senang penyair memiliki sepeda sehingga penyair berkata //akan kujaga sepedaku// //supaya tidak cepat rusak//.Petanda dari penanda puisi di atas secara keseluruhan menunjukkan bahwa aku (penyair) hormat pada keluarga (ayah) dan mencintai barang yang diberikan oleh keluarga (ayah).

Puisi lainnya yang bertema kepemilikan berjudul "Ayamku" karya Surista siswa SD 2 Blahbatuh Gianyar. Tema kepemilikan berkaitan puisi ini digambarkan ke dalam dua bait puisi yang masing-masing terdiri atas tiga baris. 
Ayamku

Aku punya ayam kecil

Warna-warni

Ibu membelikan di pasar

Akan aku pelihara ayamku

Supaya cepat besar

Tak akan aku lupa untuk memberi makan (hal. 9)

Penanda bahasa yang sifatnya sedehana (ciri dunia anak) tampak di dalam puisi di atas. Pada bait pertama terjadi kombinasi bunyi vokal (asonansi) a, i, dan e yang mencerminkan kegembiraan //aku punya ayam kecil// yang //warna-warni// yang dalam kenyataan sekarang memang banyak pedagang menjual anak ayam yang beraneka berwarna dan disenangi oleh-anakanak. Penyair semakin senang mempunyai anak ayam karena anak ayam itu dibelikan oleh ibunya di pasar //ibu membelikan dimpasar//. Rasa cinta dan senang memiliki anak ayam yang berwarna, sehingga penyair berkata: //akan aku pelihara ayamku//, //supaya cepat besar//, //tak akan aku lupa untuk memberi makan//. Dunia anak tampak tergambar kuat di dalam puisi ini, yakni dengan pemakaian diksi-diksi yang sederhana tetapi sanggup mengungkapkan kesenangan penyair memiliki anak ayam. Petanda puisi adalah bahwa anak-anak mencintai dan menyayangi setiap pemberian sesuatu oleh seorang ibu.

\section{c) Tema Lingkungan Hidup}

Tema lingkungan hidup juga merupakan tema terbanyak ketiga di dalam puisi anak-anak di dalam tabloid Lintang tahun 2017, yakni 8 puisi $(13,3 \%)$. Tema ini tampaknya berkaitan dengan tema sebelumnya, yaitu keindahan alam. Tema lingkungan hidup disampaikan oleh anak-anak bernuansa kritik lingkungan. Hal ini dapat dipahami karena anak-anak ingin lingkungan hidup yang dilihat di sekitarnya indah tidak rusak atau kotor. Salah satu puisi tersebut karya Windy Apasari siswa SD 18 Dangin Puri Denpasar sebagai berikut.
Hujan
Hujan...
Turun dengan lebat
Semuanya jadi basah
Jalan jadi becek
Bahkan bencana banjir terjadi
Akibat ulah manusia
Banyak korban bencana
Semoga saja hujan tidak tambah deras
Supaya rumah saya tidak kebanjiran (hal.1)

Puisi di atas dari sudut penanda bahasa, terutama dari diksinya kurang memiliki estetis. Hal ini dapat dimengerti karena puisi itu adalah puisi tentang kritik lingkungan yang mengutamakan pesan daripada estetika. Keadaan yang digambarkan di dalam puisi tersebut merupakan keadaan nyata yang ada di kota Denpasar apabila hujan turun. Asumsi ini disebabkan karena penyair berasal dari Denpasar. Pada bait pertama, ketika//turun hujan lebat//di kota Denpasar //semuanya jadi basah// yang mengakibatka //jalan jadi becek//. Tampaknya bait pertama ini hanya bersifat informatif saja, tidak memiliki pola estetis dan hanya penggambaran keadaan jalan apabila hujan turun. Kritik lingkungan baru muncul secara kuat pada bait kedua. Akibat hujan turun dengan lebat, kota Denpasar tidak hanya 'becek'//bahkan bencana banjir terjadi// yang diakibatka $\mathrm{n}$ oleh perilaku manusia //akibat ulah manusia// yang tidak bisa memelihara lingkungan hidup. Akibatnya, terjadi //banyak korban bencana// yang merugikan masyarakat. Puisi ini ditutup dengan harapan penyair menghadapi bencana banjir di Denpasar //semoga saja hujan tidak tambah deras//, //supaya rumah saya tidak kebanjiran//. Inilah harapan sederhana, polos, dan lugas dari anak-anak dalam menghadapi keadaan lingkungan sosial di sekitarnya. Petanda dari puisi tersebut adalah bahwa semua orang harus mencintai dan memelihara lingkungan hidupnya.

Puisi "Hujan" di atas tampaknya memiliki pesan yang sama dengan puisi karya I Gusti Putu Rinandari siswa SD Wirya Sedana Blahbatuh Gianyar yang berjudul "Banjir". Baris keenam puisi "Hujan" di atas //akibat ulah manusia// diperjelas ulah yang dimaksud yaitu //membuang sampah sembarangan// pada baris kedelapan puisi "Banjir" berikut.

Banjir

Hujan turun dengan lebat

Banyak air menggenang

Got-got pun penuh dan meluap

Ada banyak sampah di sana

Jalan pun mulai kebanjiran

Ini semua ulah manusia

Yang tidak bertanggungjawab

Membuang sampah sembarangan

Akibatnya terjadi bencana banjir (hal. 2)

Tema lingkungan hidup juga diekspresikan oleh IB Ide Yogi Swara siswa SD Saraswati 4 Denpasar berjudul "Hutan" yang mengungkapkan 
tentang kecintaan penyair kepada hutan. Perhatikanlah puisi tersebut berikut.

\section{Hutan}

Oh hutan yang asri

Aku takut jika kau tak ada

Kalau kau tak ada

Aku akan makan apa?

Kau harus tetap ada

Supaya aku tidak kelaparan (hal. 33)

Penanda bahasa pada puisi di atas menarik karena dari dari segi bentuk hanya terdiri atas satu bait dan semuanya menggunakan gaya bahasa personifikasi 'hutan' dianggap sebagai 'kau' yang merupakan kata ganti orang kedua tunggal dan gaya bahasa repetisi (kata 'tak ada'). Gaya bahasa ini digunakan untuk mengesankan bahwa aku (penyair) sangat membutuhkan dan tergantung kepada 'kau' (hutan) dan penegasan melalui gaya bahasa repetisi. Puisi tersebut memiliki nilai estetis yang kuat dengan penggunaan permainan bunyi vokal (asonansi) a, u, dan i. Puisi diawali dengan kekaguman penyair terhadap hutan //oh hutan yang asri//. Penggunaan kata 'asri' untuk merujuk kepada keadaan hutan yang tidak hanya lestari, tetapi juga indah. Penyair (aku) takut hutan yang masih 'asri' menjadi rusak atau hilang //aku takut jika kau tak ada//, //kalau kau tak ada// penyair dan masyarakat secara luas khawatir tidak bisa makan dan hidup //aku akan makan apa?//. Pertanyaan pernyair ini untuk menegaskan pentingnya hutan bagi kehidupan manusia. Oleh karena itu, penyair berharap agar //kau harus tetap ada//. Apabila 'kau' tetap ada dan asri, maka kehidupan akan berjalan dengan baik dan //supaya aku tidak kelaparan//. Petanda puisi ini merupakan kritik lingkungan agar manusia selalu menjaga keasrian lingkungan hidup agar kehidupan bisa berlangsung dengan baik.

\section{Simpulan}

\section{DAFTAR PUSTAKA}

Damono, Sapardi Djoko. 1978. Sosilogi Sastra: Sebuah Pengantar. Jakarta: Pusat pembinaan dan Pengembangan Bahasa

Dinas Kebudayaan Provinsi Bali. 2017. Impianku Antologi Puisi Anak. Denpasar: Dinas Kebudayaan Provinsi Bali

Djojosuroto, Kinayati. 2006. Pengajaran puisi Analisis dan Pemahaman. Bandung: Nuansa

Fananie, Zainudin. 2000. Telaah Sastra. Surakarta: Mohamadyah University Press.

Noth, Winfried. 1990. Handbook of Semiotics. Bloomington: Indiana University Press.

Pradopo, Rachmat Djoko. 1995. Beberapa Teori Sastra, Metode Kritik, dan Penerapannya. Yogyakarta: Pustaka Pelajar

Segers, Rien T. 1978. The Evaluation of Literary Text. Lisse: The Peter de Ridder Press.

Zaimar, Okke K.S. 2008. Semiotik dan Penerapannya dalam Karya Sastra. Jakarta: Pusat Bahasa Departemen Pendidikan Nasional. 